\title{
Heritability of progeny size in a terrestrial isopod: transgenerational environmental effects on a life history trait
}

\author{
MJ Carter ${ }^{1}$, MA Lardies ${ }^{1}$, RF Nespolo ${ }^{2}$ and F Bozinovic ${ }^{1}$ \\ ${ }^{1}$ Departamento de Ecología, Center for Advanced Studies in Ecology and Biodiversity, Pontificia Universidad Católica de Chile. Santiago \\ 6513677, Chile; ${ }^{2}$ Instituto de Ecología y Evolución, Facultad de Ciencias, Universidad Austral de Chile, Casilla 567, Valdivia, Chile
}

\begin{abstract}
Maternal effects, the environment that mothers provide to their offspring, their provision of nutrients and the environment that offspring of the same clutch share, have come to be recognized as an important influence on offspring fitness. In addition, in invertebrates, maternal effects and common environment may change according to a mother's diet. We tested for the changes in quantitative genetic parameters in a half-sib design where mothers were fed diets varying in nutrient content. Surprisingly, we found that not only maternal and common environmental variance changed with
\end{abstract}

experimental diets but also there were significant changes in narrow-sense heritabilities, with corresponding $h^{2}$ values of 0.61 (high protein), 0.08 (high carbohydrate) and 0.001 (equal carbohydrate:protein). Our results show how an environmentally driven evolutionary process could occur in nature, since the response to selection could change dramatically according to the composition of the diet that females are ingesting.

Heredity (2004) 93, 455-459. doi:10.1038/sj.hdy.6800523

Published online 14 July 2004

Keywords: maternal effects; narrow-sense heritability; animal model; phenotypic plasticity; terrestrial isopod; evolutionary process

\section{Introduction}

Animals live and reproduce in changing environments (Endler, 1986). Organisms face this environmental fluctuation in a variety of ways, and frequently they demonstrate phenotypic plasticity in several of their organismal attributes (Via et al, 1995). However, environment can also affect the way that traits are inherited; maternal and general environmental effects are a known example. The environment that mothers provide to their offspring, as well as their provision of nutrients, has been recognized to be an important influence on offspring performance (Mousseau and Fox, 1998, 2000). This is especially true for animals with direct development including a maternal care period, as in many arthropods (Fox and Czesak, 2000).

The environmental effect on the additive genetic variances of life history traits in invertebrates has received extensive treatment (Ebert et al, 1993; Barata and Baird, 1998; Mousseau et al, 2000; Pfrender and Lynch, 2000; Hunt and Simmons, 2002). Nevertheless, few studies have explored the effect of the mother's specific environment (eg mother's diet) on offspring phenotype (Fox, 1997; Fox et al, 2001). A little known, yet interesting, phenomenon is the modification of genetic parameters (ie heritabilities and maternal-environmental

Correspondence: MA Lardies, Departamento de Ecología, Facultad de Ciencias Biológicas, Center for Advanced Studies in Ecology $\mathcal{E}$ Biodiversity, Pontificia Universidad Católica de Chile, Santiago 6513677 Chile.E-mail:mlardies@genes.bio.puc.cl

Received 14 October 2003; accepted 14 January 2004; published online 14 July 2004 variance) due to changes in the mother's diet. Such a case would provide support for the hypothesis that the response to selection would change as a function of available diets, which, in turn, may change both spatially and seasonally. As far as we know, only one study has been published suggesting this pattern (Kause et al, 2001).

A key life history trait for many arthropods is progeny size, since it has an important effect on starvation resistance of larvae (Torres-Vila and Rodriguez-Molina, 2002), locomotor performance (Gibert et al, 2001), defense against predators (Fox and Czesak, 2000) and the determination of subsequent growth rate (Lawlor, 1976). Hence, progeny size (measured either for eggs or offspring) has effects on individual performance, and therefore on fitness (Fox, 2000; Fox and Czesak, 2000). Parental care is a strong determinant of progeny size in invertebrates (Lawlor, 1976; Fox and Czesak, 2000; Hunt and Simmons, 2002; Rauter and Moore, 2002; Torres-Vila and Rodriguez-Molina, 2002), particularly for isopods, where the marsupium provides a microenvironment where nutrients and minerals are translocated to offspring (Warburg, 1993; Helden and Hassall, 1998). Being detritivores, terrestrial isopods usually face low protein diets and fluctuating food availability (Warburg, 1993; Lavy et al, 2001). It is known that the proportion of protein in offspring diet can exert important effects on their performance (Torres-Vila and Rodriguez-Molina, 2002). In this paper, we go one step further by hypothesizing that mothers provided with experimental diets varying in protein content will change the genetic parameters of their progeny. According to the model proposed by Hartl et al (1985) and reviewed in Hoffmann 
and Merilä (1999), morphological traits increase their additive genetic variance under low nutrient conditions since phenotypic differences among genotypes are increased in limiting resource conditions. Since the carbohydrate content of diets is important for the formation of exoskeleton (Harrison, 1990; Helden and Hassall, 1998), low carbohydrate diets could be considered as an unfavourable environment for this species. Consequently, we predict that the offspring of females fed with low carbohydrate will exhibit higher additive genetic variance than those under control and high carbohydrate treatments.

\section{Materials and methods}

\section{Animals and study site}

Porcellio laevis is widely distributed in Chile and in several other areas throughout the world (Leistikow and Wägele, 1999). The individuals utilized for this experiment were obtained from Estación de Investigaciones Ecológicas Mediterráneas, the University terrestrial station in San Carlos de Apoquindo ( $\left.33^{\circ} 23^{\prime} \mathrm{S} ; 70^{\circ} 31^{\prime} \mathrm{W}\right)$. The station is located $20 \mathrm{~km}$ to the east of Santiago, in the Andean foothills, and encompasses roughly 835 ha (for a complete description of the study site see Jaksic, 2001). Isopods were collected by hand from under stones, pieces of wood and soil litter. All specimens were placed in plastic containers and transferred to the laboratory in the Department of Ecology of the Pontificia Universidad Católica de Chile.

\section{Maintenance and culture}

Individuals were sexed and later assigned to one of three different diet treatments (see Table 1). The gross energy of each diet was determined using a Parr 1261 computerized calorimeter, with three replicates per treatment. Diets were isocolaric (ie differences in calories between treatments were less than $3 \%$ ), with average values of $18.8 \pm 0.12,18.1 \pm 0.07$ and $18.9 \pm 0.14 \mathrm{~kJ} / \mathrm{g}$ for the control (equal carbohydrate:protein), high carbohydrate and high protein diets, respectively. For diet treatments and before pairings, each female was maintained isolated during 2 months. Three females and one male (a half-sib design) were placed in a Petri dish (50 mm of diameter; base layer of plaster of Paris). In all, 30 replicate Petri dishes were placed in each experimental condition. All treatments were maintained in an environmental chamber $\left(21^{\circ} \mathrm{C}, 14 \mathrm{~L}: 10 \mathrm{D}\right)$. We placed females and males together to allow fertilization and egg extrusion by the females. Given that females of terrestrial isopods can store sperm from several males (Moreau et al, 2002), we used only the second clutch of each isolated female (the first one was discarded to avoid any possibility of sperm storage after the isolation).

Offspring were fixed in $50 \%$ alcohol immediately following emergence from the maternal marsupium. We measured offspring size as the total length of offspring (ie the distance between the mid-dorsal anterior margin of the carapace and the distal margin of the pleotelson). Females and their offspring were measured using a compound microscope equipped with a calibrated ocular micrometer.

\section{Estimation of heritability}

We used an animal model (MTDFREML software) procedure (Boldman et al, 1995). This procedure yields direct heritabilities and genetic additive and environmental variances. We followed the general notations and model fitting procedures outlined in Dohm et al (2001). Our breeding design allowed us to estimate three variance components: $A$, the additive variance; $C$, the postnatal common environmental variance, including nonadditive effects; and $\mathrm{E}$, the environmental variance. We present results for the complete model (ACE), which includes maternal effects (both prenatal and postnatal, see Dohm et al, 2001) and nonadditive components, and the reduced model (AE) without maternal effects or nonadditive components, in each case we include real variance component values (ie not as a proportion of the total phenotypic variance)

To test the significance of maternal effects, we constrained the ACE model to the AE model and performed a likelihood ratio test (LRT). According to Shaw and Geyer (1997), the appropriate LRT for variance components is a one-tailed test. In this case, the critical $\chi^{2}$ at $P=0.05$ is 2.706 and 4.605 , with one and two degrees of freedom, respectively (Shaw and Geyer, 1997; Dohm et al, 2001). For genetic effects: (1) we constrained the ACE model to a CE model to test the significance of additive genetic effects, (2) we constrained the AE model to an $\mathrm{E}$ model to test the significance of additive genetic effects without considering maternal effects on the full model, and (3) we constrained the ACE model to an E model to test the significance of animal effects with two degrees of freedom (ie total genetic effects + maternal effects) (Dohm et al, 1996, 2001).

To compare statistically genetic parameters between treatments, we followed a procedure modified from (Shaw, 1991; see also Roff, 1997, p 103). We proceeded in

Table 1 Composition of the experimentally purified control, high carbohydrate and high protein diets

\begin{tabular}{|c|c|c|c|c|c|c|}
\hline \multirow[t]{2}{*}{ Ingredients } & \multicolumn{2}{|c|}{ Control } & \multicolumn{2}{|c|}{ High carbohydrate } & \multicolumn{2}{|c|}{ High protein } \\
\hline & Grams & $\%$ & Grams & $\%$ & Grams & $\%$ \\
\hline Soy protein & 137.5 & 27.5 & 25 & 5 & 250 & 50 \\
\hline Cornstarch & 137.5 & 27.5 & 250 & 50 & 25 & 5 \\
\hline$\alpha$-Cellulose & 189 & 37.8 & 189 & 37.8 & 189 & 37.8 \\
\hline Vitamin mix & 1 & 0.2 & 1 & 0.2 & 1 & 0.2 \\
\hline Vegetable oil & 35 & 7 & 35 & 7 & 35 & 7 \\
\hline Total & 500 & 100 & 500 & 100 & 500 & 100 \\
\hline
\end{tabular}

For each ingredient weights are expressed in grams on an air-dry basis and percentages (\%) are based on total dry weight. 
a manner analogous to a one-way ANOVA where all effects are evaluated first, and then the specific means are compared in an a posteriori test. The overall analysis consisted in comparing the log likelihood (LL) of the pooled sample (ie all three treatments considered as a single population) with the sum of the three LL values estimated separately (see Shaw, 1991). The difference between the sum of likelihoods and the pooled likelihood was compared with a $\chi^{2}$ distribution with one degree of freedom, with a significance level of 0.05 . Next, we performed the 'a posteriori' test, using pairwise sequential Bonferroni-corrected comparisons (Rice, 1989) with the same LRT procedure to evaluate which pairs of treatments were statistically different.

\section{Results and discussion}

The proportion of protein in the mother's diet had significant effects on offspring size $\left(H_{2,1263}=18.7\right.$; $P=0.0001$, Kruskal-Wallis test). Multiple comparisons of mean ranks showed that individuals born from mothers fed with equal proportions of protein and carbohydrates (ie control diet) were larger than those born from mothers fed with a lower proportion of protein to carbohydrate (ie low protein diet treatment), which, in turn, were larger than those that born from mothers fed with a higher proportion of protein to carbohydrate (ie high protein diet treatment; $P<0.001$ for all pairwise comparisons). The reduced size of the offspring in the high protein treatment is expected, given the known effect of carbohydrate on exoskeleton in the young (Harrison, 1990; Helden and Hassall, 1998). Since our high protein treatment was low in carbohydrates, this probably produced comparatively smaller individuals. Genetic analysis showed that both narrow-sense heritabilities $\left(h^{2}\right)$ and maternal and common environmental variance $\left(c^{2}\right)$ changed with the composition of diets (Table 2). Only the high protein diet yielded a large and significant $h^{2}$, whereas both the control diet and low protein diet treatment produced low and nonsignificant $h^{2}$, and high $c^{2}$ (Table 2). Significant differences were found among the three genetic analyses (overall $\chi^{2}=13.5$; $P=0.0002)$ with the high protein treatment differing significantly from the control treatment $\left(\chi^{2}=12.2\right.$; $P=0.0003)$, following sequential Bonferroni correction. Neither low protein versus high protein nor low protein versus control treatment comparisons were significant following sequential Bonferroni correction (although both were significant at $\alpha=0.1$ ).

Life history traits have low $h^{2}$, either as a result of Fisher's fundamental theorem of natural selection, according to which the rate of increase of fitness of any organism at any time is equal to its genetic variance in fitness at that time', thus, fitness traits are expected to have low levels of additive genetic variance due to rapid fixation of alleles conferring highest fitness (Fisher, 1930; Gustaffson, 1986) or because fitness-related traits may have higher residual variance (ie environmental and

Table 2 (a) Heritabilities $\left(h^{2}\right)$ and maternal effect $\left(c^{2}\right)$ values for each treatment, (b) statistics of the fit to the animal model procedure and (c) significances computed by likelihood ratio tests

\begin{tabular}{|c|c|c|c|c|}
\hline Treatment & High carbohydrate & High protein & Control & Total (diet as a fixed effect) \\
\hline$h^{2} \pm \mathrm{SE}$ & $0.08 \pm 0.36$ & $0.61 \pm 0.39 *$ & $0.001 \pm 0.29$ & $0.06 \pm 0.12$ \\
\hline$c^{2} \pm \mathrm{SE}$ & $0.47 \pm 0.19^{* *}$ & $0.11 \pm 0.17$ & $0.38 \pm 0.15^{* * *}$ & $0.41 \pm 0.07^{* * *}$ \\
\hline$e^{2} \pm \mathrm{SE}$ & $0.46 \pm 0.19$ & $0.28 \pm 0.24$ & $0.62 \pm 0.16$ & $0.53 \pm 0.07$ \\
\hline$V_{\mathrm{A}}$ & 0.0023 & 0.0153 & 0.00001 & 0.0017 \\
\hline$V_{\mathrm{C}}$ & 0.0143 & 0.0028 & 0.0111 & 0.0118 \\
\hline$V_{\mathrm{E}}$ & 0.0141 & 0.0070 & 0.0180 & 0.015 \\
\hline$V_{\mathrm{P}}$ & 0.031 & 0.025 & 0.029 & 0.029 \\
\hline \multicolumn{5}{|l|}{$-2 * L L$} \\
\hline ACE & -1248.4 & -1079.0 & -1337.3 & -3631.7 \\
\hline $\mathrm{CE}$ & -1248.3 & -1076.2 & -1337.3 & -1631.4 \\
\hline $\mathrm{AE}$ & -1240.1 & -1078.6 & -1326.8 & -1513.2 \\
\hline E & -1059.7 & -975.6 & -1209.8 & -3210.4 \\
\hline \multicolumn{5}{|l|}{ Descriptive data } \\
\hline Sires & 25 & 18 & 23 & 66 \\
\hline Dams & 54 & 45 & 59 & 158 \\
\hline Offsprings & 349 & 296 & 394 & 1039 \\
\hline Total animals & 428 & 359 & 476 & 1263 \\
\hline Mean \pm SD (offspring, mm) & $1.76 \pm 0.18$ & $1.73 \pm 0.17$ & $1.79 \pm 0.17$ & $1.76 \pm 0.17$ \\
\hline Min-Max (offspring, mm) & $1.19-2.19$ & $1.19-2.15$ & $1.15-2.35$ & $1.15-2.35$ \\
\hline
\end{tabular}

$h^{2}=$ (direct) narrow-sense heritability; $c^{2}=$ common environmental and maternal proportion of total variance; $e^{2}=$ environmental proportion of total variance; $\mathrm{SE}=$ asymptotic standard error; $V_{\mathrm{A}}=$ additive genetic variance; $V_{\mathrm{C}}=$ common environmental and maternal variance; $V_{\mathrm{E}}=$ residual variance; $\mathrm{ACE}$ model $=$ full model including additive genetic variance+common environmental and maternal variance+environmental (residual) variance; $\mathrm{CE}=$ reduced model excluding additive genetic effects; $\mathrm{AE}=$ reduced model excluding common environmental and maternal variance; $\mathrm{E}=$ reduced model excluding both additive genetic effects and common environmental and maternal variance (assuming purely environmental effects). Twice the LL value approximates a $\chi^{2}$ distribution. Likelihood ratio tests (Lynch and Walsh, 1998) were performed to evaluate whether estimates were significantly different than zero, with degrees of freedom equal to the number of parameters dropped from the model. According to Shaw and Geyer (1997) (see also Dohm et al, 2001) this is a one-tailed test, where critical $\chi^{2}$ values are 2.706 and 4.605 with one and two degrees of freedom, respectively.

${ }^{*} P<0.05$.

$* * P<0.01$.

$* * * P<0.001$ 
nonadditive genetic variances) and consequently low heritability due to more complex genetic architecture than traits more distantly associated with fitness (Price and Schluter, 1991; Merilä and Sheldon, 1999). Overall, our results (ie considering the entire data set and including diets as a fixed effect) are in agreement with this general pattern.

However, we did find a surprisingly high value of heritability in one of our experimental diets (ie high protein, $h^{2}=0.61$ ), which contrasts with the general pattern observed in life history traits (Mousseau and Roff, 1987), but is in agreement with what is known for crustaceans (Pfrender and Lynch, 2000). This may be due, in part, to the low maternal effects obtained in the high carbohydrate and control treatments. Alternatively, the expression of additive genetic variation could increase in unfavourable conditions (Hoffmann and Merilä, 1999). Actually, the high protein diet presented an additive genetic component one order of magnitude larger than any of the other treatments. Since the amount of carbohydrate in the diet is important for the formation of exoskeleton (Helden and Hassall, 1998; Harrison, 1990), the diet with low content of carbohydrate could be considered as a 'stressful environment'. This condition could increase the expression of additive genetic variance by reducing environmental variance as results suggest (see Table 2; Hoffmann and Merilä, 1999).

Our results support the generalized view of maternal/ common environmental effects as strong determinants of progeny size (Mousseau and Fox, 1998, 2000), and these findings may apply to other herbivorous arthropods, since the proportion of nitrogen in animal biomass is usually much higher than that of plants (Awmack and Leather, 2002). For herbivorous arthropods, available dietary nitrogen (in the form of protein and free amino acids) can potentially limit many important processes (McNeill and Southwood, 1978; White, 1993; Joern and Behmer, 1997). A potential shortcoming of our conclusions may arise from two facts. First, we forced individuals to consume the experimental diets. Second our design cannot distinguish from pure maternal and common environmental variance.

With regard to the first issue, Joern and Behmer (1997) showed that a grasshopper species could select diets with more carbohydrate content, and both Hassall and Rushton (1984) and Warburg (1993) describe behavioural diet selection by terrestrial isopods. Whether $P$. laevis selects its diets according to the nutrient content is not known. However, this phenomenon would be important for determining the potential for selection on progeny size of $P$. laevis, depending on three main facts: (1) the annual reproductive pattern of this species, (2) according to this pattern, the seasonal basis of nitrogen and carbohydrate availability in the environment, which, in turn, depends on the plant species present in the ambient, and (3) the scale of spatial heterogeneity that $P$. laevis experiences. Most of this information has not been collected, which incites a call for more field studies with regard to the physiological ecology of this species.

With regard to the second issue (the differentiation between maternal and common environmental effects), the proportional contributions of maternal and common environmental effects to progeny size do not change our general conclusion: diet consumed by the mother could change dramatically the form of inheritance in progeny size. Certainly, we cannot draw conclusions with regard to the extent of variance in progeny size that is due to translocations of nutrients from the mother (a prenatal maternal effect), or the contrary, how important is the shared environment of the offspring in determining their size (a pure common environmental effect). Such information would be valuable especially in the scenario of the effects of favourable and unfavourable environments on response to selection (see Hoffmann and Merilä, 1999).

Maternal and common environmental effects were highly variable among experimental diets, which, in turn, induced strong differences in heritabilities. Differences in genetic variances due to environment have been reported for Daphnia (Ebert et al, 1993), the seed beetle (Fox et al, 1999) and the sawfly (Kause et al, 2001). Furthermore, our results are in concordance with studies that report changes in maternal effects with the specific environment of the mother (Barata and Baird, 1998; Rauter and Moore, 2002). Some authors have reported intergenerational effects of mothers on life history patterns and trade-offs (Ebert et al, 1993; Fox, 1994, 1997; Rauter and Moore, 2002); nevertheless, our results suggest a rather different outcome: intergenerational effects can interfere with genetic effects. With regard to standard evolutionary theory, this would mean that the environment experienced by a mother, which may change on a seasonal and/or unpredictable basis (Kause et al, 2001), could determine how and when a trait responds to natural selection (Hoffmann and Merilä, 1999). Several lines of evidence are in agreement that progeny size could be a target of selection (Lawlor, 1976; Barata and Baird, 1998; Fox and Czesak, 2000; Fox et al, 2001; Torres-Vila and Rodriguez-Molina, 2002) and that maternal and common environmental effects could modify the response to selection (Fox and Czesak, 2000; Rauter and Moore, 2002), both in favourable and unfavourable environments (Hoffmann and Merilä, 1999). Hence, our initial hypothesis suggesting the existence of environmentally driven evolutionary processes would be supported by our results.

\section{Acknowledgements}

PE Neill provided valuable comments that greatly improved the manuscript. Financial support was provided by a CONICYT doctoral thesis fellowship to MAL and by FONDAP 1501-001 Program 1 to FB.

\section{References}

Awmack CS, Leather SR (2002). Host plant quality and fecundity in herbivorous insects. Ann Rev Entomol 47: 817-844.

Barata C, Baird DJ (1998). Phenotypic plasticity and constancy of life-history traits in laboratory clones of Daphnia magna Straus: effects of neonatal length. Funct Ecol 12: 442-452.

Boldman KG, Kriese LA, Van Vleck LD, Van Tassell CP, Kachman SD (1995). A Manual for Use of MTDFREML. US Department of Agriculture, Agricultural Research Service: Lincoln.

Dohm MR, Hayes JP, Garland T (1996). Quantitative genetics of sprint running speed and swimming endurance in laboratory house mice (Mus domesticus). Evolution 50: 1688-1701. 
Dohm MR, Hayes JP, Garland T (2001). The quantitative genetics of maximal and basal rates of oxygen consumption in mice. Genetics 159: 267-277.

Ebert D, Yampolsky L, Stearns SC (1993). Genetics of life history in Daphnia magna I. Heritabilities at two food levels. Heredity 70: 335-343.

Endler JA (1986). Natural Selection in the Wild. Monographs in Population Biology. Princeton Univ. Press: New Jersey, vol 21.

Fisher R (1930). The Genetical Theory of Natural Selection A complete varorium edition (1999). Oxford University Press: New York.

Fox CW (1994). Maternal and genetic influences on egg size and larval performance in a seed beetle (Callosobruchus maculatus): multigenerational transmission of a maternal effect? Heredity 73: 509-517.

Fox CW (1997). The ecology of body size in a seed beetle, Stator limbatus: persistence of environmental variation across generations? Evolution 51: 1005-1010.

Fox CW (2000). Natural selection on seed-beetle egg size in nature and the laboratory: variation among environments. Ecology 81: 3029-3035.

Fox CW, Czesak ME (2000). Evolutionary ecology of progeny size in arthropods. Ann Rev Entomol 45: 341-369.

Fox CW, Czesak ME, Mousseau TA, Roff DA (1999). The evolutionary genetics of an adaptive maternal effect: egg size plasticity in a seed beetle. Evolution 53: 552-560.

Fox CW, Czesak ME, Fox R (2001). Consequences of plant resistance for herbivore survivorship, growth, and selection on egg size. Ecology 82: 2790-2804.

Gibert P, Huey RB, Gilchrist GW (2001). Locomotor performance of Drosophila melanogaster: interactions among developmental and adult temperatures, age, and geography. Evolution 55: 205-209.

Gustaffson L (1986). Lifetime reproductive success and heritability: empirical support for Fisher's fundamental theorem. Am Nat 128: 761-764.

Harrison KE (1990). The role of nutrition in maturation, reproduction and embryonic development of decapod crustaceans: a review. J Shell Res 9: 1-28.

Hartl DL, Dykhuizen DE, Dean AM (1985). Limits of adaptation: the evolution of selective neutrality. Genetics 111: 655-674.

Hassall M, Rushton SP (1984). Feeding behaviour of terrestrial isopods in relation to plant defences and microbial activity. In: The Biology of Terrestrial Isopods. Symposia of the Zoological Society of London: Oxford, No 53, pp 487-504.

Helden AJ, Hassall M (1998). Phenotypic plasticity in growth and development rates of Armadillidium vulgare (Isopoda: Oniscoidea). Isr J Zool 44: 379-394.

Hoffmann AA, Merilä J (1999). Heritable variation and evolution under favourable and unfavourable conditions. Trends Ecol Evol 14: 96-101.

Hunt J, Simmons LW (2002). The genetics of maternal care: direct and indirect genetic effects on phenotype on the dung beetle Onthophagus taurus. Proc Natl Acad Sci USA 99: 6828-6832.

Jaksic F (2001). Spatiotemporal variation patterns of plants and animals in San Carlos de Apoquindo, central Chile. Rev Chil Hist Nat 74: 459-484.

Joern A, Behmer ST (1997). Importance of dietary nitrogen and carbohydrates to survival, growth, and reproduction in adults of the grasshopper Ageneotettix deorum (Orthoptera: Acrididae). Oecologia (Berl) 112: 201-208.
Kause A, Saloniemi I, Morin JP, Haukioja E, Hanhimäki S, Ruohomäki K (2001). Seasonally varying diet quality and the quantitative genetics of development time and body size in birch feeding insects. Evolution 55: 1992-2001.

Lavy D, Van Rijn MJ, Zoomer HR, Verhoef HA (2001). Dietary effects on growth, reproduction, body composition and stress resistance in the terrestrial ispods Oniscus asellus and Porcellio scaber. Physiol Entomol 26: 18-25.

Lawlor LR (1976). Parental investment and offspring fitness in the terrestrial isopod, Armadillidium vulgare (Latr.) (Crustacea: Oniscoidea). Evolution 30: 775-785.

Leistikow A, Wägele JW (1999). Checklist of the terrestrial isopods of the new world (Crustacea, Isopoda, Oniscidea). Rev Bras Zool 16: 1-72.

Lynch M, Walsh B (1998). Genetic and Analysis of Quantitative Traits. Sinauer Press: Massachusetts.

McNeill S, Southwood TRE (1978). The role of nitrogen in the development of the insect/plant relationship. In: Harboneed J (ed) Biochemical Aspects of Plant and Animal Coevolution. Academic Press: London, pp 77-98.

Merilä J, Sheldon BC (1999). Genetic architecture of fitness and nonfitness traits: empirical patterns and development of ideas. Heredity 83: 103-109.

Moreau J, Seguin S, Caubet Y, Rigaud T (2002). Female remating and sperm competition patterns in a terrestrial crustacean. Anim Behav 64: 569-577.

Mousseau T, Roff D (1987). Natural selection and the heritability of fitness components. Heredity 59: 181-197.

Mousseau T, Fox CW (1998). The adaptive significance of maternal effects. Trends Ecol Evol 13: 43-407.

Mousseau T, Fox CW (2000). Maternal Effects as Adaptations. Oxford University Press: New York.

Mousseau TA, Sinervo B, Endler JA (2000). Adaptive Genetic Variation in the Wild. Oxford University Press: New York.

Pfrender ME, Lynch M (2000). Quantitative genetic variation in Daphnia: temporal changes in genetic architecture. Evolution 54: 1502-1509.

Price T, Schluter D (1991). On the low heritability of life-history traits. Evolution 45: 853-861.

Rauter CM, Moore AJ (2002). Evolutionary importance of parental care performance, food resources, and direct and indirect genetic effects in a burying beetle. J Evol Biol 15: 407-417.

Rice WR (1989). Analyzing tables of statistical tests. Evolution 43: 223-225.

Roff DA (1997). Evolutionary Quantitative Genetics. Chapman \& Hall: Montreal.

Shaw FH, Geyer CJ (1997). Estimation and testing in constrained covariance component models. Biometrika 84 95-102.

Shaw RG (1991). The comparison of quantitative genetic parameters between populations. Evolution 45: 143-151.

Torres-Vila LM, Rodriguez-Molina MC (2002). Egg size variation and its relationship with larval performance in the Lepidoptera: the case of the European grapevine moth Lobesia botrana. Oikos 99: 272-283.

Via S, Gomulkiewicz R, De Jong G, Scheiner SM, Schlichting CD, Van Tienderen PH (1995). Adaptive phenotypic plasticity: consensus and controversy. Trends Ecol Evol 10: 212-217.

Warburg MR (1993). Evolutionary Biology of Land Isopods. Springer-Verlag: Berlin.

White TCR (1993). The Inadequate Environment: Nitrogen and the Abundance of Animals. Springer: Heidelberg. 